\title{
sciendo
}

\section{Key drivers and skills need for innovative companies focused on sustainability}

\author{
Adriana GRIGORESCU \\ National School for Political and Administrative Studies, \\ Correspondent Member of Academy of Romanian Scientists \\ adrianagrigorescu11@gmail.com \\ Monica Mihaela MAER MATEI \\ The Bucharest University of Economic Studies, \\ National Scientific Research Institute for Labour and Social Protection \\ matei.monicamihaela@gmail.com \\ Cristina MOCANU \\ National Scientific Research Institute for Labour and Social Protection \\ mocanu@incsmps.ro \\ Ana-Maria ZAMFIR \\ National Scientific Research Institute for Labour and Social Protection \\ anazamfir@incsmps.ro
}

\begin{abstract}
Innovation is essential for European competitiveness and provides key inputs for developing business models that are conducive for a more sustainable economy. Recent evidences show that businesses have increased the management attention and investments they're dedicating to sustainability. This paper aims to identify the most important drivers supporting companies to develop innovation activities oriented towards making the business models more sustainable. We explore microdata from the 2016 Innobarometer "EU Business Innovation Trends" (Flash Eurobarometer 433), covering 14,112 companies from 30 countries. Using statistical classification methods, we identify the most important factors that are related to innovation activities that have potential to shape the efficiency of raw materials usage and the environmental protection. Special focus is given to companies' investments in training, software development, research and development, company branding, design of products and services, organization or business process improvements and acquisition of machines, equipment, software or licenses. Also, our analysis highlights the skills that are needed the most by companies in order to support their innovation activities targeting sustainability. Our results are useful for better understanding the attention that is given to sustainability by innovative companies and which are the main factors that boost innovation dedicated to sustainability.
\end{abstract}

Keywords: sustainable development, innovation, skills, resources efficiency, classification methods

\section{Introduction}

An innovative business model refers to new and innovative ways that help companies to create and capture value, supporting firms to change the way they do business in order to secure a sustained competitive advantage (Mudaly, 2016; Amit \& Zott, 2001). Evidences show that innovation represents a key capability of companies that aim to improve their competitive advantage, while supporting sustainability (Wrigley, Bucolo \& Straker, 2016). 
On the other hand, in the context of deterioration and pollution of the environment, transition to a more sustainable economic system has become highly desirable (Geissdoerfer, Vladimirova \& Evans, 2018). In long term, companies applying a sustainable business model can become more resilient in face of various risks (Choi \& Wang, 2009), diversifying their production processes. Recent evidences show that businesses have increased the management attention and investments they're dedicating to sustainability.

PICBE $\mid 718$

Sustainable oriented business innovation represents a topic of great interest as there is still a research gap with respect to the implementation of this business model, its tools and challenges (Geissdoerfer, Vladimirova \& Evans, 2018). This paper aims to identify the most important drivers supporting companies to develop innovation activities oriented towards making the business models more sustainable. We explore microdata at company level from 30 countries. Using statistical classification methods, we identify the most important factors that are related to innovation activities that have potential to shape the efficiency of raw materials usage and the environmental protection. Special focus is given to companies' investments in training, software development, research and development, company branding, design of products and services, organization or business process improvements and acquisition of machines, equipment, software or licenses. Also, our analysis highlights the skills that are needed the most by companies in order to support their innovation activities targeting sustainability. Our results are useful for better understanding the attention that is given to sustainability by innovative companies and which are the main factors that boost innovation dedicated to sustainability.

\section{Literature review}

Over the recent decades, companies changed their attitude towards sustainability, becoming more aware that sustainable practices also can boost their success, being financially rewarding. Innovation is one of the companies' means to reach an improved position on the market, while supporting the transition to a more sustainable economy. Different terms / concepts have been introduced in order to define this process, such as sustainable innovation, sustainability-driven innovation, eco-innovation, etc., but their definitions are still not completely agreed on. (Wehnert \& all, 2018). Research on the drivers of sustainability-oriented innovation is rather at the beginning, different research papers identifying one specific factor or strategy supporting its processes. At first, papers were more focused on the behavior of large companies, but during the recent years several steps were made in analyzing the SMEs practices (Klewitz, Hansen, 2013).

The urge for companies to promote sustainability-oriented innovation emerge at the intersection of the need to comply with social and environmental regulations, with the need to benefit from new business opportunities provided by sustainability targets.

Sustainability-oriented innovation implies that companies have the intention to develop products and services that aim to support economic, environmental and social sustainability (Gauthier, 2005; Hansen \& all, 2009; Feniser \& all, 2017). In this context, the management commitment to sustainability goals is a core factor to develop sustainabilityoriented innovation (Paech, 2007, Hansen \& all, 2009, Klewitz, Hansen, 2013)

But only intentions are not enough. Hansen \& all (2009) exemplify how a "life cycle dimension" is needed in order to reach the long-term goals of sustainability-oriented innovation: the entire value chain has to be considered, from accessing resources, to 
production process, employed technologies, obtained products and services and their impact on sustainability.

Impact of recent developments on the sustainable goals still has to be measured and studied, the literature becoming more focused on these issues. However, it is hard to believe that individual companies possess the needed knowledge and understanding on the longterm consequences of their operations on sustainability. So, the company knowledge management is another key factor hat foster sustainability-oriented innovations (MelaneLavado, Alvarez-Herranz, 2018). The knowledge needed by companies in order to develop innovations under the aims of sustainability can be addressed though the existing skills and experts (Petruzzelli \& all, 2011), but also research and development activities have a significant influence, irrespective of the fact that they are performed in-house or subcontracted. Companies with external links, including foreign direct investments, seem to be more oriented, both towards innovation as well as towards sustainability goals (Wehnert \& all, 2018).

Other researchers pointed out to the role of the stakeholders' participation in order to coherently incorporate sustainable goals within companies' products and services production (Wehnert \& all, 2018). As the pressure on companies to develop sustainable operations increases, and the stakeholders became more diverse, the strategy to develop open innovation practices becomes a rational choice.

Studies aiming to analyze the SMEs practices on sustainability-oriented innovation have showed that SMEs are more focused on environmental issues and more committed to eco-innovation, being less involved in social or ethical issues (Klewitz \& Hansen, 2013; Ghenta \& Matei, 2018). Therefore, company size could be a predictor for companies' commitment to sustainability-oriented innovation.

\section{Methodology}

We explore microdata from the 2016 Innobarometer "EU Business Innovation Trends" (Flash Eurobarometer 433), covering 14,112 companies from 30 countries - Finland, Greece, Ireland, Belgium, Switzerland, Poland, Portugal, Netherlands, Croatia, United Kingdom, Romania, Latvia, France, Spain, United States, Czech Republic, Bulgaria, Denmark, Italy, Austria, Sweden, Luxembourg, Slovakia, Lithuania, Cyprus, Hungary, Germany, Malta, Estonia, Slovenia. The sample includes all types of companies, from micro-enterprises to large companies. The objective of the survey was to collect data on innovation activities of the companies, as well as on industrial modernization. The interviews have been conducted in 2016. Analysis have been performed on unweighted data.

We have employed a classifier in order to understand which are the most important factors separating the companies whose innovations may positively impact resource efficiency, environmental protection and construction solutions for future smart cities from other firms not necessarily oriented towards sustainability. The factors included in the estimation are as follows:

- size of the firm (size)

- percentage of company's turnover invested in innovation activities (invest)

- percentage of total turnover invested in training (training)

- percentage of total turnover invested in software development (software) 
- percentage of total turnover invested in company reputation and branding, including web design (branding)

- percentage of total turnover invested in Research and development (R\&D) (RD)

- percentage of total turnover invested in Design of products and Services (design)

- percentage of total turnover invested in Organization or business process improvements (processImprove)

PICBE $\mid 720$

- percentage of total turnover invested in Acquisition of machines, equipment, software or licenses (equipment).

The dependent variable (y) was built on the item regarding the potential impact of innovation activities on different areas. The companies that selected at least one of the following: resource efficiency, environmental protection or construction solutions for future smart cities belong to the positive class of companies that through innovation practices drive sustainability $(y=Y e s)$. The companies included in the second class $(y=N o)$ are the ones considering that their innovations will impact other areas, not related to sustainability, such as: job creation, IT and digital economy, lifelong learning and skills improvement, space applications, health and medical care, transport and transport infrastructures, availability and quality of food.

The selection of the methodology employed for investigating the factors supporting companies to develop innovation activities oriented towards a sustainable economy was based on the following aspects:

1) The number of companies in the positive class is outnumbered by the companies included in the negative class. We are dealing with an unbalanced dataset, which will affect the classification results that are overwhelmed by the dominant events. In brief, information coming from the rare cases is ignored. This issue was addressed in the literature by re-sampling the original dataset (Chawla et al., 2002).

2) In order to find which are the features playing an important role when trying to discriminate between the two categories of companies, a good classifier is needed. It is important to obtain classification results that provide information regarding the predictors importance.

With respect to the first issue, in order to balance class distribution, we are going to use a solution based on smoothed bootstrap technique referred to as ROSE (Random Over Sampling Examples), (Lunardon, Menardi, Torelli, 2014). This approach, implies that new artificial data is drawn from the two conditional kernel density estimates of the classes. We have chosen this approach because it has shown good performance compared to other existing methods, reducing the risk of model overfitting (Menardi, Torelli, 2014).

Regarding the second aspect, among the classification methods, we have selected the decision trees for interpretability and visualization considerations. Given the reduced level of predictive accuracy, obtained when trying to separate the two categories of companies on the features described before, we improved our prediction model through bootstrap technique by using a random forest approach Breiman (2001). Instead of building a single decision tree, the results from a large number of trees is combined, deriving a classifier with a substantially improved predictive performance. In a nutshell, this involves building B decision trees using B bootstrapped training sets. Each tree is grown deep, hence not pruned. Moreover, a different random sample of predictors is taken at each split. Typically, the number of predictors considered at each split is approximately equal to the square root of 
the total number of predictors. These operations aim to reduce variance by averaging a large number of uncorrelated trees. Furthermore, fitting nonlinearities and interactions is one of the main advantages of random forest.

For a specific observation, each of the B trees will predict a specific class. The overall prediction for that company will be the class occurring most often. For a certain tree of $B$, the estimation is made on a bootstrapped subset of the observations. This means that some of the observations, known as "out of bag" (OOB), are not included in this specific training set but are used for error estimation. The predicted class of a specific entity will then be produced from the trees where it was an OOB. The importance of each predictor is measured by the mean decrease of the node impurity, computed by Gini index, when that predictor serves as a splitting variable (James et al., 2013).

\section{Results and discussions}

Around one half of the manufacturing companies have used or have the intention to use (in the next 12 months) advanced technologies. Considering that the share of companies showing industrial modernization is not very high, it is relevant to know how many companies use advanced technologies aiming the efficiency of raw materials usage and the environmental protection. Innobarometer data show that only $31.1 \%$ of manufacturing companies have used technologies that address sustainability related goals. Also, 30.2\% of the manufacturing companies have the intention to use sustainable technologies in the near future. These results show a reduced potential for fast progress in this area (Figure 1).

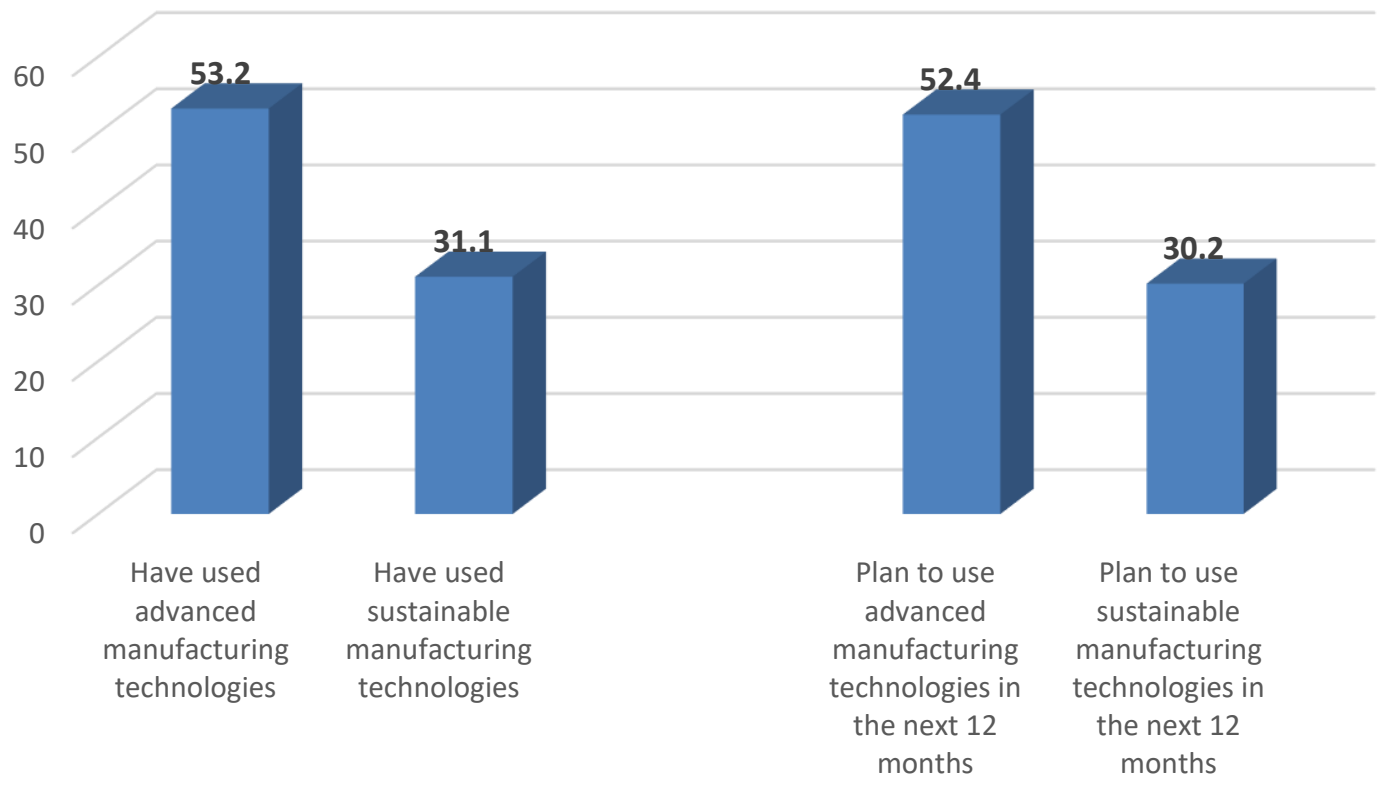

Figure 1. Usage and usage intention of sustainable technologies among manufacturing companies (\%)

Source: 2016 Innobarometer, Authors' own research results

In this context, innovation activities become crucial not only for increasing the competitive advantage of the companies, but also for addressing sustainability related goals. 
It is important to better understand which are the main drivers influencing sustainableoriented innovation activities in companies. The estimation was performed using randomForest library in R (Breiman et al., 2011). The number of trees trained is 1000 and the number of variables tried at each split is 3 . Within this framework, the OOB estimate of the error rate is $19.53 \%$. AUC (Area Under the Receiver Operating Characteristic (ROC) curve), the measure used to evaluate the performance of the estimator is 0.86 , describing a good model, that can accurately distinguish between the two categories (Figure 2).

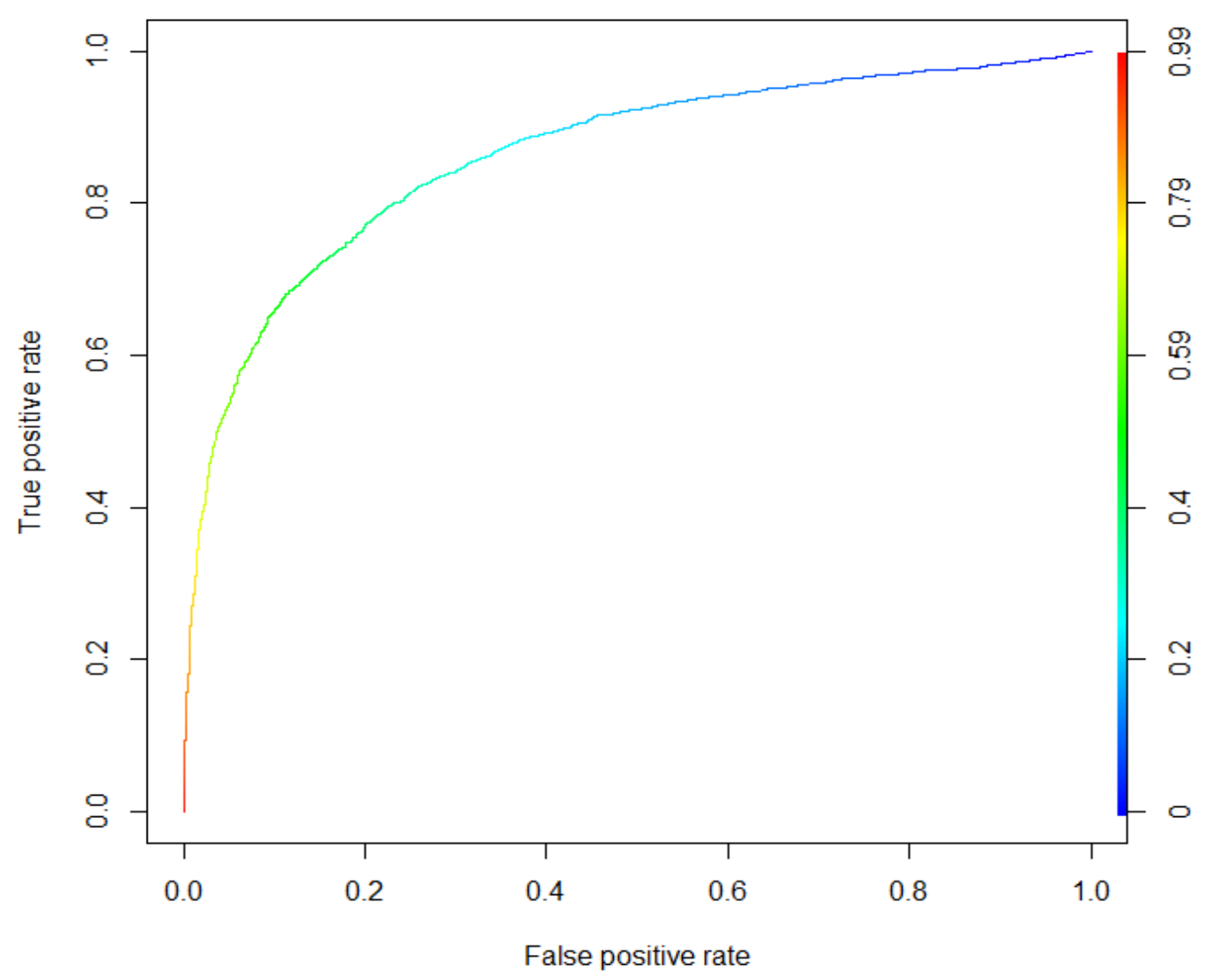

Figure 2. ROC curve

Source: 2016 Innobarometer, Authors' own research results

In order to emphasize the factors discriminating among the positive and negative classes, two measures of variable importance are reported. The first is based upon the mean decrease of accuracy in predictions on the out of bag samples when a given predictor is excluded from the model. The latter is a measure of the total decrease in node impurity that results from splits over that variable, averaged over all trees.

The variables with the largest mean decrease in Gini index are: percentage of company's turnover invested in innovation activities (invest), percentage of total turnover invested in Design of products and Services (design), percentage of total turnover invested in acquisition of machines, equipment, software or licenses (equipment), percentage of total 
turnover invested in software development (software). The results indicate that across all of the trees considered in the random forest, the size of the company (size) is the most important variable, if the criterion is the mean decrease of accuracy (Figure 3).

PICBE | 723

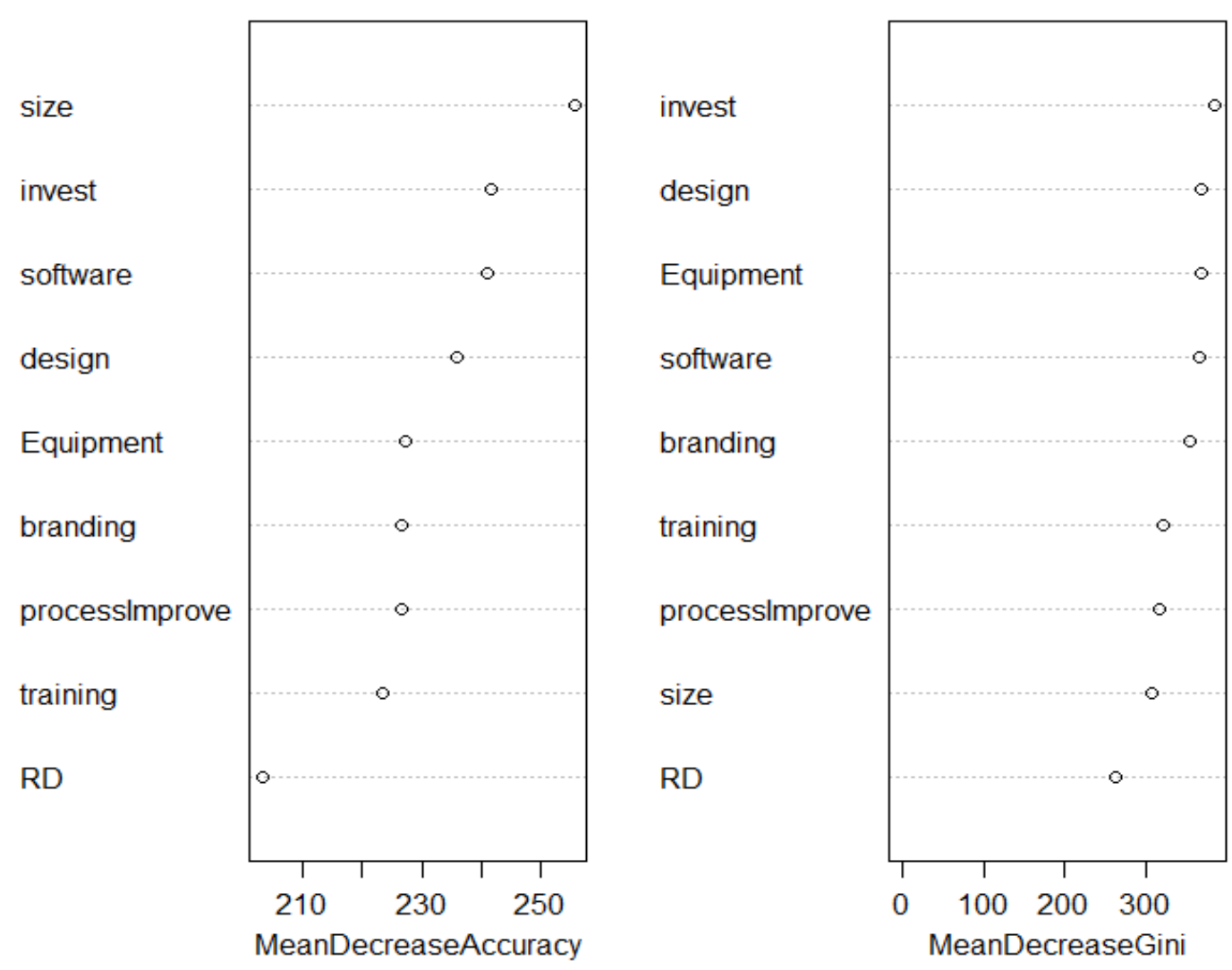

Figure 3. Variable importance

Source: 2016 Innobarometer, Authors' own research results

The marginal effect of the variables on the class probability $(y=N o)$ is shown in the partial dependence plots. For each category, the partial dependence is computed using the average predictions obtained when that category is maintained constant for all instances. For the company size, all the categories show a positive effect but the magnitude differ. For the small companies, with less than 9 employees, the model predicts a higher probability of the negative class. For the companies in the category 250-499 employees, we observe that the negative class is less likely (Figure 4). 


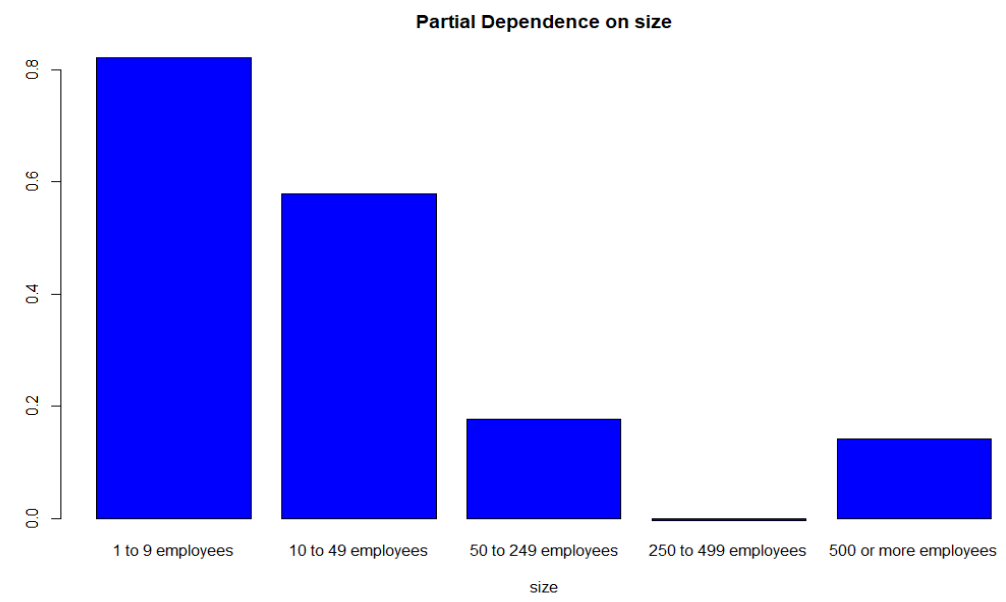

PICBE | 724

Figure 4. Partial dependence on company size

Source: 2016 Innobarometer, Authors' own research results

For the other important factors, the partial dependence plots suggest that reduced levels of investments involve a higher probability of not undertaking innovation activities targeting sustainability (Figure 5).
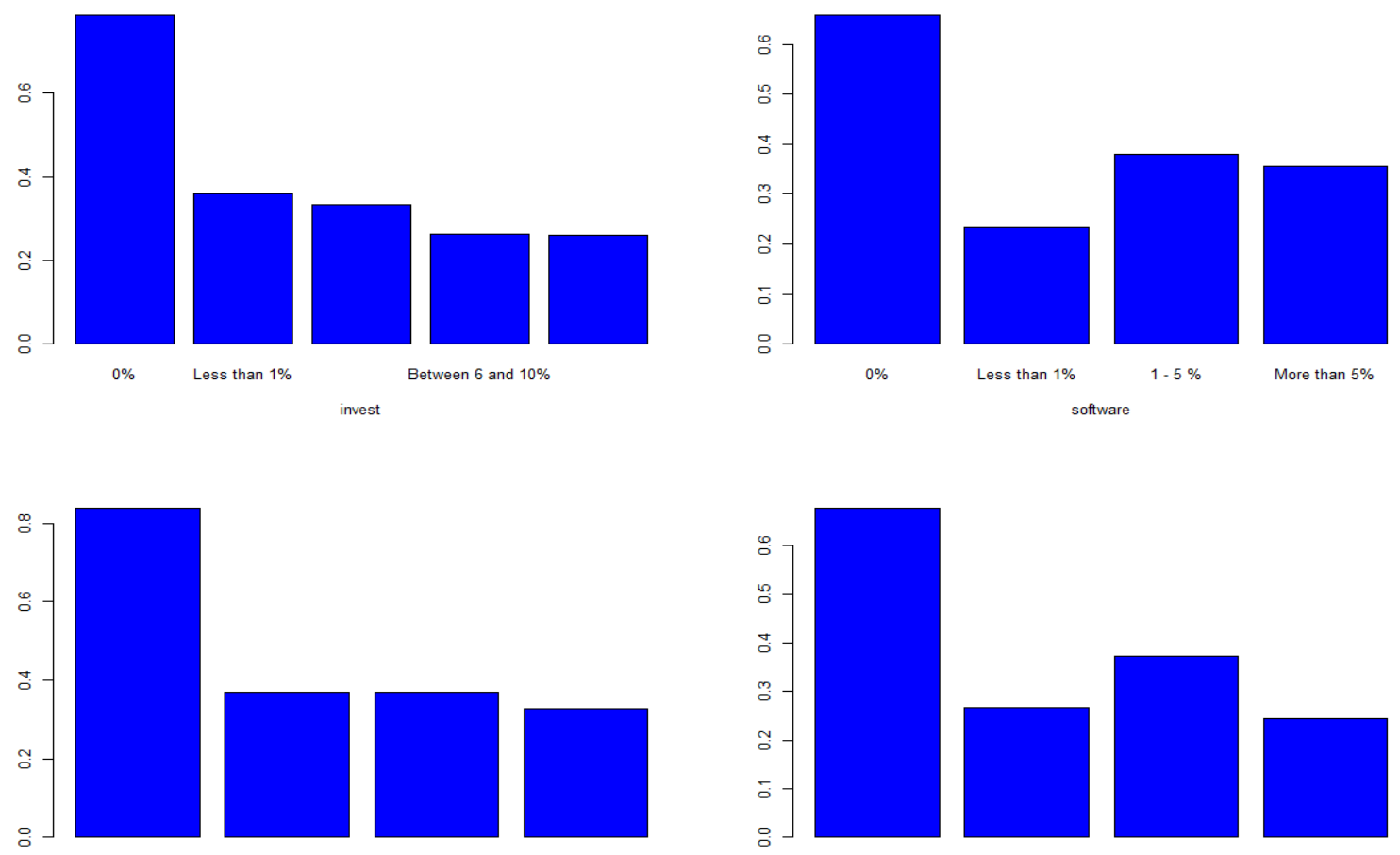

Less than $1 \%$

$1-5 \% \quad$ More than $5 \%$

$0 \%$

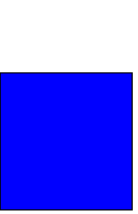

Less than $1 \%$

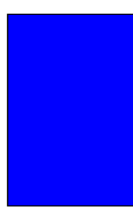

$1-5 \%$

design

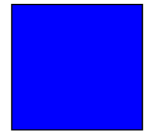

More than $5 \%$ Equipment

Figure 5. Partial dependence on percentage of company's turnover invested in innovation activities

Source: 2016 Innobarometer, Authors' own research results 
As previous studies have shown, other factors that support sustainable oriented innovation activities in companies are related to the stock of skills and knowledge. Skills needed for the improvement of innovation activities have been explored among the subsample of companies that have performed sustainability-oriented innovation activities (Figure 6). Most companies consider that strong technical skills (specific for the sector) could help improve and support company's innovation activities. Also, marketing skills have been PICBE | 725 indicated as important for boosting innovation activities at company level. Another useful class of skills refers to financial knowledge related to investment and access to funding. Management commitment manifested in the form of organizational and leadership skills could also contribute to sustainability-oriented innovation activities.

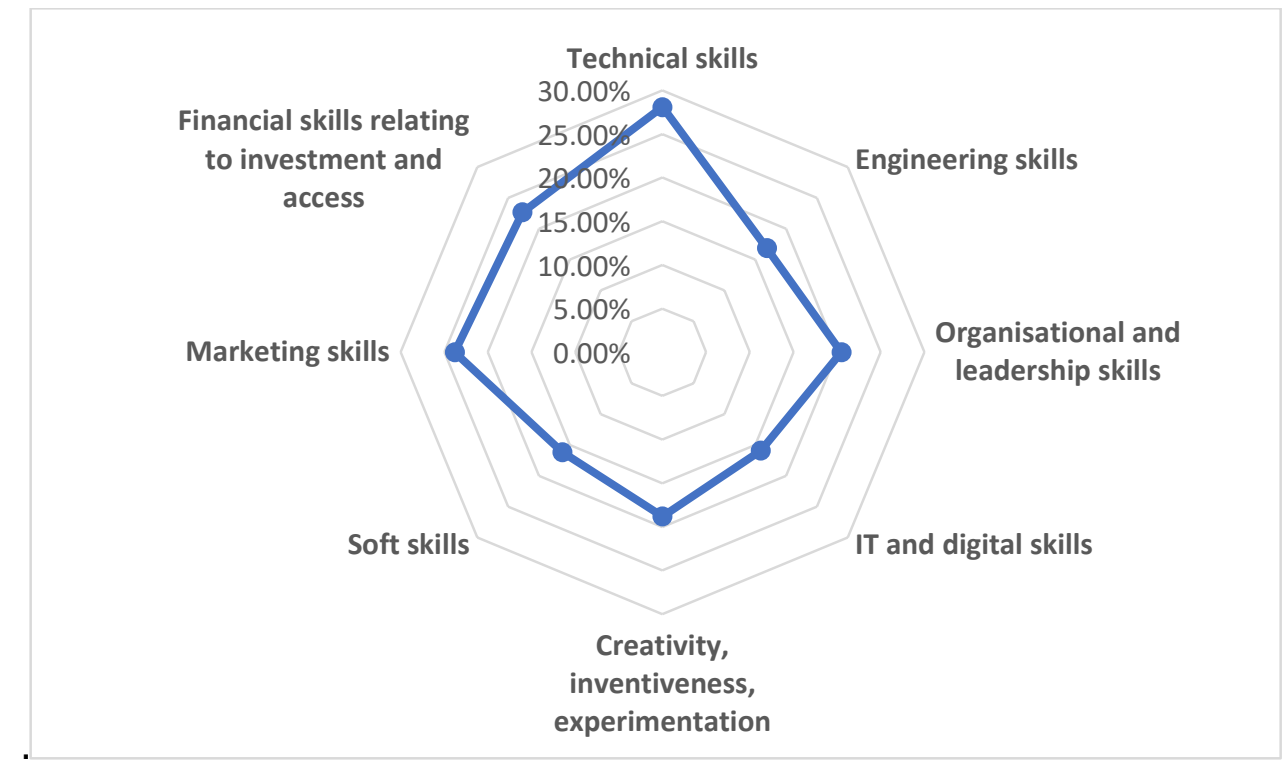

Figure 6. Skills that could help improve and support company's innovation activities over the next two years (\%)

Source: 2016 Innobarometer, Authors' own research results

\section{Conclusion}

Analyzing micro-data from the 2016 Innobarometer, this paper offers an in-depth image of the main factors defining the business model that relies on sustainability oriented innovation. First, our results confirm that innovation activities of the companies play a crucial role in the transition to a more sustainable economy. Second, we found that the business model embracing sustainability-oriented innovation is characterized by higher investments in innovation activities, design of products and Services, acquisition of machines, equipment, software or licenses and software development. Also, confirming previous findings larger companies have greater potential to innovate, while addressing sustainability goals.

From the point of view of the measures supporting innovation, skills development is considered essential by innovative companies focused on sustainability. Technical skills, marketing skills, financial knowledge and leadership are the most important skills that could make companies more capable to develop innovation activities focused on sustainability. 
Most important limitations of our research are related to the fact that we have explored only the influence of company level factors, with no reference to the regional or national context which could be also relevant (Davidescu \& all, 2015). Additionally, as we stated in the methodology section, for enhancing the robustness of our results, we have performed our analysis on unweighted data from the 2016 Innobarometer. In our future research, we aim to address these limitations by employing complementary research methods.

\section{References}

Amit, R. \& Zott, C. (2001). Value creation in e-business. Strategic Management Journal, 493520.

Breiman, L. (2001). Random forests. Machine learning, 45(1), 5-32.

Breiman, L., Cutler, A., Liaw, A., \& Wiener, M. (2011). Package randomForest. Software available at: http://stat-www. berkeley. edu/users/breiman/RandomForests.

Chawla, N. V., Bowyer, K. W., Hall, L. O., \& Kegelmeyer, W. P. (2002). SMOTE: synthetic minority over-sampling technique. Journal of artificial intelligence research, 16, 321357.

Choi, J., \& Wang, H. (2009). Stakeholder relations and the persistence of corporate financial performance. Strategic Management Journal, 30 (8), 895-907.

Davidescu, A.A., Vass Paul, A.M., Gogonea, R.M., \& Zaharia, M. (2015). Evaluating Romanian Eco-Innovation Performances in European Context. Sustainability, 7, 12723-12757.

Feniser, C., Burz, G., Mocan, M., Ivascu, L., Gherhes, V., \& Otel, C.C. (2017). The Evaluation and Application of the TRIZ Method for Increasing Eco-Innovative Levels in SMEs. Sustainability, 9, 1125.

Gauthier, C. (2005). Measuring corporate, social and environmental performance: The extended life-cycle assessment. Journal of business ethics, vol. 59 (1-2), 199-206.

Geissdoerfer, M., Vladimirova, D., \& Evans, S. (2018). Sustainable business model innovation: A review. Journal of Cleaner Production, 198, 401-416.

Ghenta, M. \& Matei, A. (2018). SMEs and the Circular Economy: From Policy to Difficulties Encountered During Implementation. Amfiteatru Economic 20, 294-309.

Hansen, E.G., Grosse-Dunker, F., \& Reichwald, R. (2009). Sustainability innovation cube - A framework to evaluate sustainability - oriented innovations. International Journal of Innovation Management, Vol. 13 (4) pp. 683-713 (2009)

James, G., Witten, D., Hastie, T., \& Tibshirani, R. (2013). An introduction to statistical learning (Vol. 112). New York: springer.

Klewitz, J., \& Hansen, E.G. (2013). Sustainability-oriented innovation of SMEs: a systematic review. Journal of Cleaner Production, Retrieved from http://dx.doi.org/10.1016/j.jclepro.2013.07.017

Lunardon, N., Menardi, G., \& Torelli, N. (2014). ROSE: A Package for Binary Imbalanced Learning. R Journal, 6(1).

Melane-Lavado, A., \& Alvarez-Herranz, A. (2018). Different Ways to Access Knowledge for Sustainability-Oriented Innovation. The Effect of Foreign Direct Investment in Sustanability, 10, 4206

Menardi, G., \& Torelli, N. (2014). Training and assessing classification rules with imbalanced data. Data Mining and Knowledge Discovery, 28(1), 92-122. 
Mudaly, N.A. (2016). Business model innovation - the drivers, enablers and inhibitors of firms facing disruptive change. University of Pretoria. Retrieved from https://repository.up.ac.za/bitstream/handle/2263/59891/Mudaly_Business_2017. pdf?sequence $=1$.

Paech, N. (2007). Directional certainty in sustainability-oriented innovation management in Lehmann-Waffenschmidt, M. (Ed.). Innovations towards Sustainability. Conditions and Consequences. Physica, Heidelberg, New York, pp. 121-140.

Petruzzelli, A.M., Dangelico, R.M., Rotolo, D., \& Albino, V. (2011). Organizational factors and technological features in the development of green innovations: Evidence from patent analysis. Innovation, Vol. 13, pp. 291-310.

Wehnert, P., Kollwitz, C., Daiberl, C., Dinter, B., \& Beckmann, M. (2018). Capturing the Bigger Picture? Applying Text Analytics to Foster Open Innovation Processes for Sustainability-Oriented Innovation. Sustainability, 10, 3710.

Wrigley, C., Bucolo, S., \& Straker, K. (2016). Designing new business models: blue sky thinking and testing. Journal of Business Strategy, 37(5), 22-31. 